\title{
Differential molecular response of maize and Johnson grass against maize dwarf mosaic virus and bermuda grass southern mosaic virus
}

\author{
F. S. MOSTAFAVI ${ }^{1}$, S. K. SABBAGH ${ }^{*}$, A. YAMCHI ${ }^{3}$, S. NASROLLANEJAD ${ }^{4}$, N. PANJEHKEH ${ }^{5}$
}

\begin{abstract}
${ }^{1}$ Plant Pathology, Department of Plant Protection, Faculty of Agriculture, University of Zabol, Iran; ${ }^{2}$ Department of Biology, Campus of Sciences, Yazd University, Iran; ${ }^{3}$ Department of Plant Breeding \& Biotechnology, Gorgon University of Agricultural Sciences \& Natural Resources, Iran; ${ }^{4}$ Department of Plant Protection, Gorgon University of Agricultural Sciences \& Natural Resources, Iran; ${ }^{5}$ Department of Plant Protection, Faculty of Agriculture, University of Zabol, Iran
\end{abstract}

Received May 9, 2018; revised July 18, 2018; accepted January 7, 2019

\begin{abstract}
Summary. - Maize dwarf mosaic virus (MDMV) and bermuda grass southern mosaic virus (BgSMV) is the most important cereal potyvirus in Iran. Expression of some key genes in maize plants susceptible and tolerant to MDMV or BgSMV and gene expression profile of MDMV and BgSMV compatible or incompatible to Johnson grass plants were studied. Time points of 1, 9,24 and $72 \mathrm{~h}$ after inoculation with both viruses were investigated as well. By analyzing the expression of the genes, it was identified that in maize infected by MDMV and BgSMV, the transcript levels of the peroxiredoxin, GLP, SAM, NPR1 and chlorophyll $a-b$ binding genes were significantly higher in the tolerant than in susceptible plants during the entire experiment. In the BgSMV inoculated Johnson grass plants, some of the genes related to plant defense responses including NPR1, peroxiredoxin and SAM had higher expression level than the Johnson grass plants inoculated by MDMV. Important genes in maize tolerance like $N P R 1$ and $M T-L P$, were analyzed by trilinear decomposition analysis and genes clustering. The upregulated expression of genes at one-hour post inoculation showed that the plant response to viruses was activated at the early stage of infection.
\end{abstract}

Keywords: MDMV; BgSMV; gene expression; quantitative real-time PCR; trilinear decomposition analysis

\section{Introduction}

Sweet corn (Zea mays L.) is a cereal grain first domesticated in Mexico. Actually, it is one of the most widely cultivated crops in Iran, used for animal feed, corn ethanol production and corn starch feeding. maize dwarf mosaic virus (MDMV) and bermuda grass southern mosaic virus (BgSMV) are the most yield-limiting factors in cultivated sweet corn varieties in Iran.

*Corresponding author. E-mail: sksabbagh@yazd.ac.ir; phone: +989133731069.

Abbreviations: BgSMV = bermuda grass southern mosaic virus; $\mathrm{dpi}=$ days after inoculation; FKBP = FK506-binding protein; GF14-6 = G-box factor 14-6; GLP = germin-like protein; hpi = hours post inoculation; MDMV = maize dwarf mosaic virus; MT-LP = metallothionein like protein; NPR1 = nonexpressor of pathogenesis related genes 1; qRT-PCR = quantitative real-time PCR; SAM = S-adenosyl methionine synthase
Both viruses are ssRNA positive strand viruses of the family Potyvirus that cause serious disease on cereals and can be spread via aphids in non-persistent transmission manner (Uzarowska et al., 2009; Masumi et al., 2011a; Cueto-Ginzo et al., 2016).

Bermuda grass mosaic virus disease is caused by two viral groups including: bermuda grass southern mosaic virus (BgSMV) and bermuda grass mosaic virus (BgMV). BgSMV has a widespread distribution across temperate and tropical regions of southern Iran. BgSMV is similar to MDMV but serological, molecular, host range and vector transmission studies had demonstrated that BgSMV is a new species of the genus Potyvirus (Zare et al., 2005). Both viruses are able to infect maize and other cereals. Johnson grass plants can be infected by MDMV and it is known as overwintering host of MDMV, however BgSMV virus is not able to infect Johnson grass plants (Masumi et al., 2011b; Mostafavi et al., 2015). 
In sensitive and tolerant plants during viral infection, the expression level of defense-related genes are altered based on genetic abilities to recognize pathogen attack (Hao et al., 2012).

The elevated expression of defense-related genes such as SAMs and G-box factor 14-6 (GF14-6) leads to production of resistance proteins which are considered as molecular responses of maize to variety of biotic stresses (Chen et al., 2006; Uzarowska et al., 2009; Campo et al., 2012).

Recently, functional genomic analysis has revealed the molecular mechanisms of virulence-related genes involved in the plant resistance pathways (Wu et al., 2013).

Microarray data analysis for gene expression profiling has shown that the expression level of some putative defense-related genes such as metallothionein-like protein, S-adenosyl methionine synthetase, germin-like protein and $26 S$ ribosomal RNA gene were increased in corn plants infected by sugarcane mosaic virus (SCMV) and MDMV (Uzarowska et al., 2009).

The post transcriptional analysis by proteomic approach has demonstrated a high expression level of peroxiredoxin and ascorbate peroxidase genes in maize infected with sugarcane mosaic virus (Wu et al., 2013).

Metallothionein-like protein, S-adenosyl methionine synthetase, germin-like protein, chlorophyll $a$ - $b$ binding protein, peroxiredoxin, FK506-binding protein (FKBP), GF 14-6 and $N P R 1$ genes are involved in different points of plant defense signaling pathways and response to stress including metabolism and photosynthesis processes.

Metallothionein proteins (MTs) with a low molecular weight and rich in cysteines are known to play an important role in the regulation of metabolic pathways and also to detoxify heavy metals in maize (Hamer, 1986; Singh et al., 2011). Increase of germin-like proteins (GLPs) encoded by multigene families has been reported in several plant species stressed by biotic factor as pathogenic agents and insect feeding and also by application of different biologically active compounds such as salicylic acid, $\mathrm{H}_{2} \mathrm{O}_{2}$ or ethylene (Marathe et al., 2004; Lane, 2002; Zimmermann et al., 2006). Ethylene is responsible for plant disease resistance signaling pathways and S-adenosyl methionine synthase (SAMs) which is a key enzyme in ethylene biosynthesis (Gomez-Gomez and Carrasco, 1998).

Peroxiredoxins $(\operatorname{Pr} x)$ are thiol-dependent antioxidant enzymes that play primary roles in the regulation of peroxide levels in cellular redox signaling (Haslekas et al., 2003).

G-box factor 14-6 (GF14-6) as a member of 14-3-3 family contributes to enhanced defense mechanisms and also is able to influence biological processes involved in stress-related mechanisms (Gökirmak et al., 2010; Oh et al., 2010; Campo et al., 2012). Ability of GF14-6 gene to recognize parts of viral coat protein has been demonstrated and important regulatory role of this gene during plant defense has been suggested (Konagaya et al., 2004).
The role of FKBPs genes have been recently demonstrated in plant stress tolerance and immunology (Wang et al., 2012). In many plants, FKBPs genes are a critical regulators of biotic and abiotic stress response and normal growth and development (Hartl and Hayer-Hartl, 2002).

Gene expression analysis by quantitative real-time PCR (qRT-PCR) using defense-related genes could be a reliable way of improving plant tolerance to certain abiotic stress factors as viral infection. Some genes are consistently expressed in plants and are altered at stress conditions. In this study, the expression level of some key genes in both susceptible and tolerant maize genotypes against MDMV and BgSMV were studied. Also, we evaluated the expression levels of these genes in Johnson grass plants compatible or incompatible to MDMV and BgSMV to illustrate the role of these genes in virus host adaptation.

\section{Materials and Methods}

Plant material and virus infection. The seeds of maize SC705 cultivar susceptible to MDMV and BgSMV and 8-hybrid seeds (KLM75010/4-4-1-2-1-1-1×MO17) from cultivar tolerant to the both viruses were used. Maize and Johnson grass seeds were obtained from Agricultural and Natural Resources Research Center of Golestan province, Iran. Seeds were surface sterilized in 3\% chloramines T (Sigma, France) for $5 \mathrm{~min}$ and washed three times in sterile distilled water. Surface sterilized seeds were planted in plastic pots $(20 \mathrm{~cm}$ deep $\times 15 \mathrm{~cm}$ top diameter) containing autoclaved sand-loam-clay soil (1:2:1). The plants were cultured in greenhouse under controlled conditions at $25-28^{\circ} \mathrm{C}$ for 15 days before virus inoculation and were protected against insect attack. Maize and Johnson grass plants were mechanically inoculated with MDMV (GenBank Acc. No. JQ280313) and BgSMV (GenBank Acc. No. KU372146) particles at the three-leaf stages and were maintained in a separate greenhouse to avoid cross-contamination. Inoculums were prepared from the sap of the MDMV and BgSMV infected maize leaves in two volumes of $0.05 \mathrm{~mol} / \mathrm{l}$ phosphate buffer $\mathrm{pH} 7$ and were applied by gentle rubbing with a finger by using carborundum powder. Mock-inoculation was carried out using the inoculation buffer alone. The four parallel replications, each consisting of three pots, were performed for each treatment. Leaves were collected from MDMV and BgSMV-inoculated and mock-inoculated plants at five-time intervals $(0,1,9,24$ and $72 \mathrm{~h}$ post inoculation (hpi)). Harvested leaves from infected and control plants were immediately frozen in liquid nitrogen and then were stored at $-80^{\circ} \mathrm{C}$ until RNA extraction.

Gene expression changes. The expression levels of tested genes were measured 1, 9, 24 and 72 hpi using qRT-PCR measurement. Fifty grams of infected maize cultivar leaves at the different time intervals after inoculation were harvested for total RNA extraction by P-Biozol (Bio Flux) solution according to the manufacturer's instructions. The RNA was verified by $1.0 \%$ agarose gel 
Table 1. Primers used in qPCR

\begin{tabular}{|c|c|c|c|c|}
\hline Primer name & Sequence $\left(5^{\prime}-3^{\prime}\right)$ & $\begin{array}{l}\text { Annealing } \\
\text { temperature }\end{array}$ & $\begin{array}{l}\text { Product length } \\
\text { (bp) }\end{array}$ & Acc. No. \\
\hline Peroxiredoxin-F & CGGCAAGAAGGTCATCC & \multirow{2}{*}{$59^{\circ} \mathrm{C}$} & \multirow{2}{*}{120} & \multirow{2}{*}{ NP001149765 } \\
\hline Peroxiredoxin- $\mathbf{R}$ & AGCAGGATCTCGTCTACA & & & \\
\hline GLP-F & CGAGATCATCTTCGTCCT & \multirow{2}{*}{$59^{\circ} \mathrm{C}$} & \multirow{2}{*}{130} & \multirow{2}{*}{ AF032974 } \\
\hline GLP-R & GTTCTGCTGGAAGTGGA & & & \\
\hline GF14-6-F & GGAGCTGAGAGAAAGGA & \multirow{2}{*}{$59^{\circ} \mathrm{C}$} & \multirow{2}{*}{109} & \multirow{2}{*}{ P49106 } \\
\hline GF14-6-R & CCAGTCCAAGCCTAATAG & & & \\
\hline SAM-F & GCTGACCACTGCAAGG & \multirow{2}{*}{$59^{\circ} \mathrm{C}$} & \multirow{2}{*}{160} & \multirow{2}{*}{ BT054969 } \\
\hline SAM-R & GGCTGAGGGGCATCA & & & \\
\hline MTL-F & CGGAGGCAACTGTGG & \multirow{2}{*}{$59^{\circ} \mathrm{C}$} & \multirow{2}{*}{90} & \multirow{2}{*}{ Q5U7K6 } \\
\hline MTL-R & CCTGCTCAGCCATGTC & & & \\
\hline Chlorophyll a-b-F & CCATGTTCGGATTCTTCG & \multirow{2}{*}{$59^{\circ} \mathrm{C}$} & \multirow{2}{*}{115} & \multirow{2}{*}{ NM001154761 } \\
\hline Chlorophyll a-b-R & AAGTTGGTGGCGTAGG & & & \\
\hline NPR1-F & TACCCATCCACCGCT & \multirow{2}{*}{$59^{\circ} \mathrm{C}$} & \multirow{2}{*}{160} & \multirow{2}{*}{ NM001154115 } \\
\hline NPR1-R & CCTCCATCTTGTACCGC & & & \\
\hline FKBP-F & AGTGCCCGCTGGAG & \multirow{2}{*}{$59^{\circ} \mathrm{C}$} & \multirow{2}{*}{120} & \multirow{2}{*}{ EU958134 } \\
\hline FKBP-R & GTCGAACACCGTGCC & & & \\
\hline Actin-F & AAGAGAGGCATCCTGACA & \multirow{2}{*}{$59^{\circ} \mathrm{C}$} & \multirow{2}{*}{120} & \multirow{2}{*}{ J01238 } \\
\hline Actin-R & CAGGGTGATCTTCAGGC & & & \\
\hline
\end{tabular}

electrophoresis and quality checked by NanoDrop ${ }^{\text {Tw }} 100$ UV-V spectrophotometer (Thermo Scientific, USA). Total RNA was subjected to cDNA synthesis using Sinaclon cDNA synthesis kit (SinaClon, Iran) according to the manufacturer's protocol. Maize viral infection was verified by using a specific primer pair (MDF3:5'-GATGAGTTRAAYGTYTATGCACGAC-3' and MDR1: 5'-RTGCATRATTTGTCTGAAAGTTGG-3').

The real time reaction contained $5 \mu$ of SYBR Green PCR master mix, $2 \mu \mathrm{l}$ of cDNA template and $1 \mu \mathrm{l}$ of $10 \mu \mathrm{mol} / \mathrm{l}$ of each forward and reverse primer.

The qRT-PCR was performed in duplicates using an iCycler instrument (iQ5, BioRad, USA).

The thermal cycling condition for qRT-PCR were as follows: $5 \mathrm{~min}$ at $94^{\circ} \mathrm{C}$ followed by 40 cycles of denaturation at $94^{\circ} \mathrm{C}$ for $10 \mathrm{~s}$, annealing at $59^{\circ} \mathrm{C}$ for $10 \mathrm{~s}$ and extension at $72^{\circ} \mathrm{C}$ for $2 \mathrm{~min}$. For the standard curves, the threshold cycle $(\mathrm{Cq})$ values were calculated using the iCycler software provided by the qPCR equipment manufacturer. Melting curve analysis and electrophoresis pattern was used to determine the specificity of the PCR products. Table 1 shows the characterization of primers used in this study. The Actin was used as the house-keeping gene. For calculation of real-time efficiencies (E), the slope of the standard curve was fitted into the following equation: $\mathrm{E}=10^{-1 / \text { slope }}$. The relative changes were calculated according to $\Delta \Delta \mathrm{C}_{\mathrm{T}}$ method of Pfaffl (Pfaffl, 2001; Ludmerszki et al., 2015). The $2^{-\Delta \Delta C T}$ value was given to estimate the fold change of gene expression. Each value was the mean of three independent biological experiments. The data were analyzed using the GenEx6 software and the chart was designed by Microsoft excel software.
Trilinear (3-way) decomposition analysis. Three datasets were provided based on trilinear decomposition for two susceptible and tolerant maize plants and Johnson grass plants by GenEx6 software. The data were analyzed by trilinear decomposition which assumes that there is a limited number $(n)$ of underlying factorial expression patterns.

Three-way decomposition calculated three sets of responses: one for data columns which show the expression changes over the genes, one for rows which reflect the expression changes over the samples (combination of two viruses with four points of hpi) and one for the variable that distinguishes the data file that shows gene expression variation over the genotypes.

\section{Results}

\section{Detection of $M D M V$ and $B g S M V$}

RNAs quality determination on the agarose gel indicated a high quality of extracted RNA for qRT-PCR analysis. Single qRT-PCR product of the expected size was yielded using specific primers to MDMV and BgSMV (MDF3, MDR1) (Fig. 1a; Table 1).

Symptoms of infection and differences between the susceptible and tolerant infected maize plants were monitored for 20 days after the first inoculation. To verify the success of infection, ELISA technique was used.

Maize SC705 cultivar and Johnson grass plants showed chlorotic streaks on green tissues approximately 15 and 18 

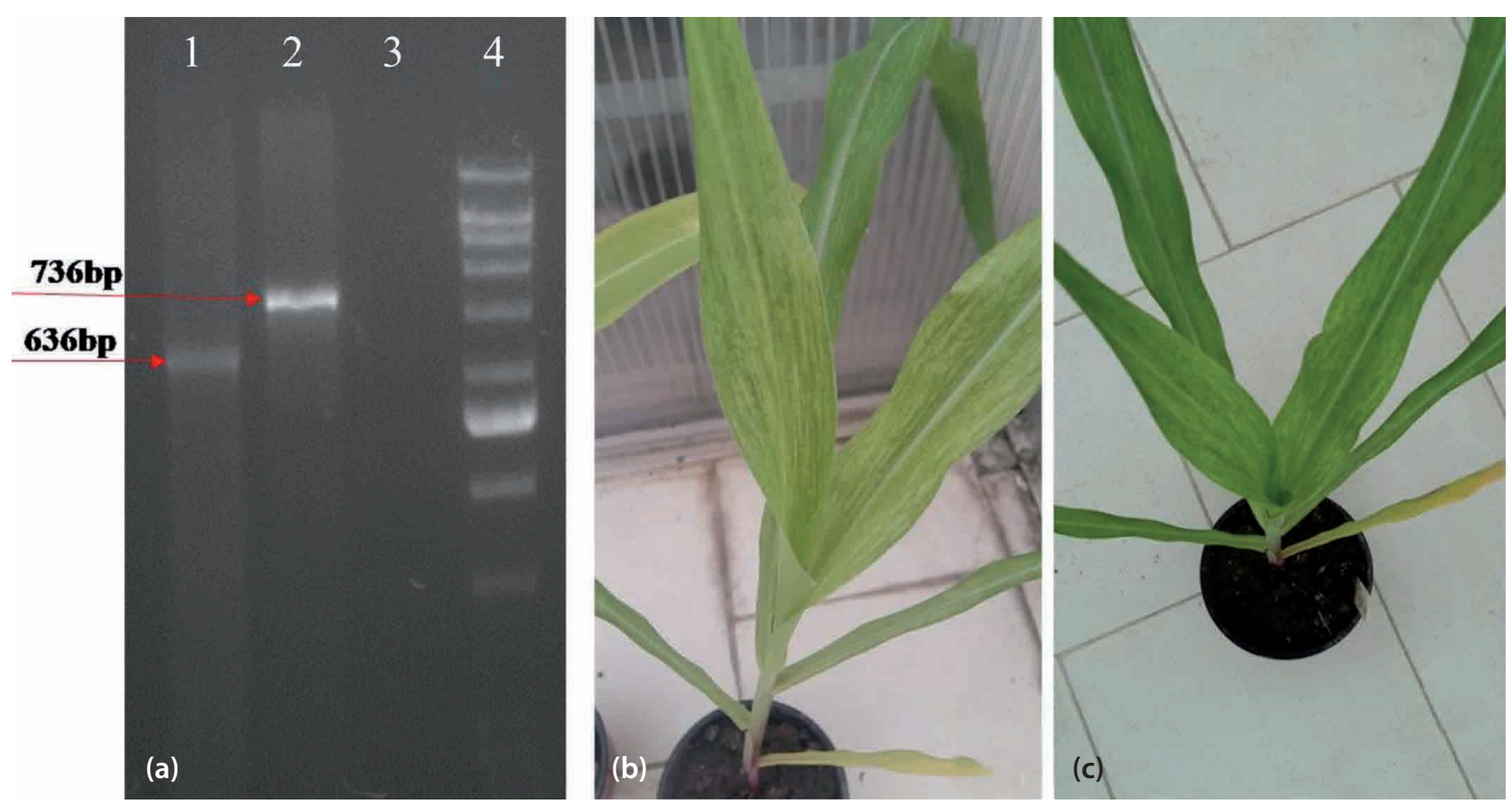

Fig. 1

MDMV and BgSMV symptoms in maize plants

(a) PCR products from infected maize with two viruses (1: MDMV, 2: BgSMV, 3: negative control, 4: DNA Ladder 100bp plus GelPilot, Qiagen). Severe mosaic symptoms in susceptible maize genotype inoculated by MDMV (b) and BgSMV (c).
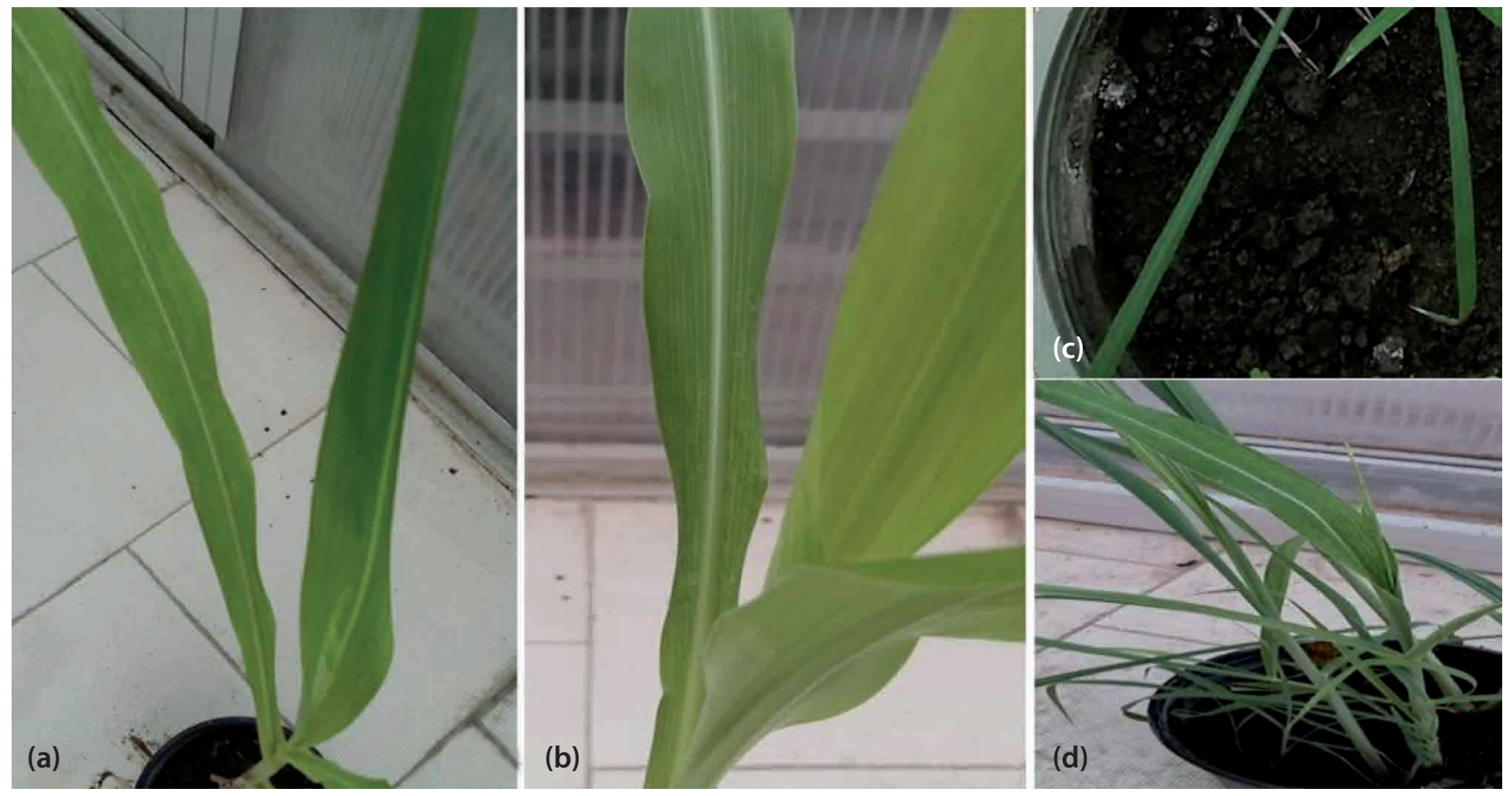

Fig. 2

Symptoms in maize and Johnson grass infected with MDMV and BgSMV

Mild mosaic in tolerant maize hybrid inoculated by MDMV (a) and BgSMV (b), mosaic symptoms in Johnson grass inoculated by BgSMV (c) and without symptoms in Johnson grass inoculated by MDMV (d). 


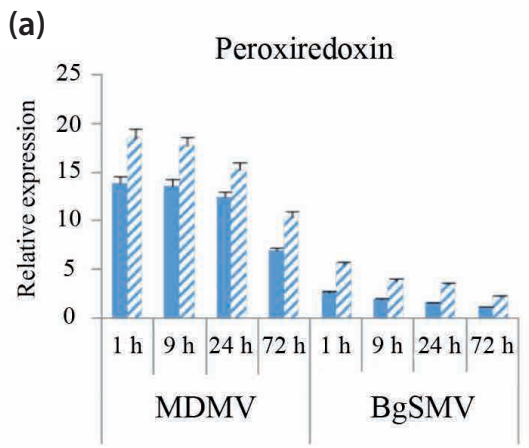

(d)

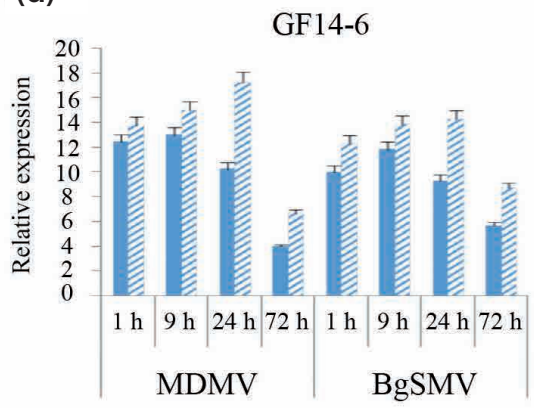

(b)

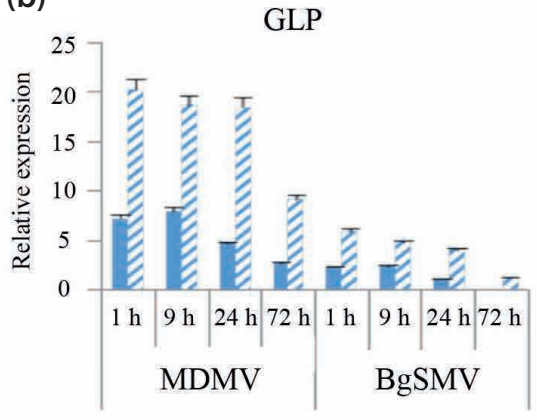

(e)

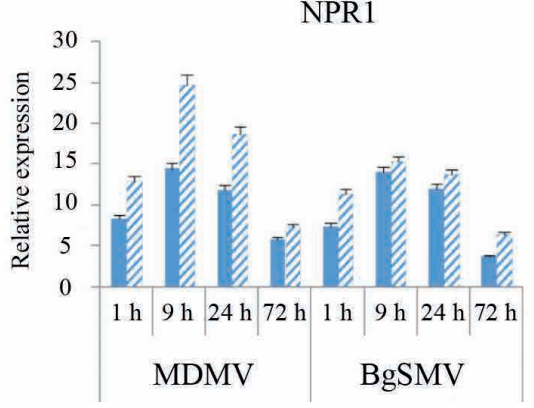

(c)

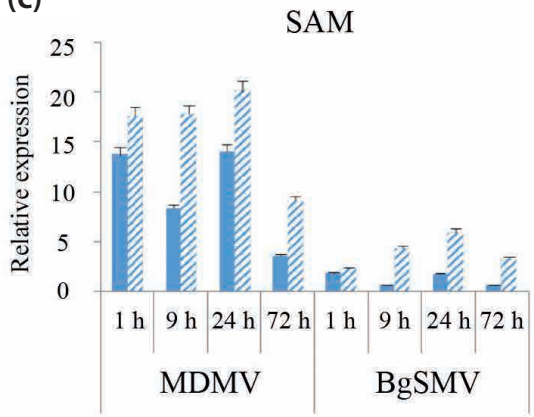

(f)

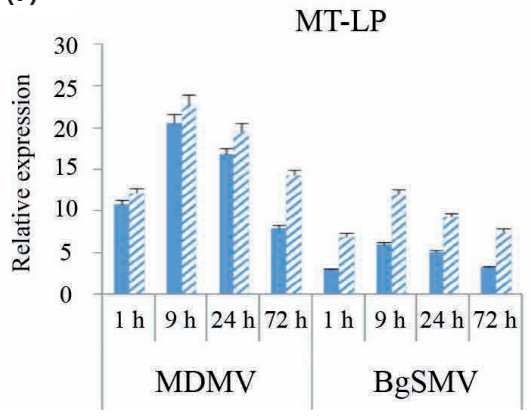

(g)

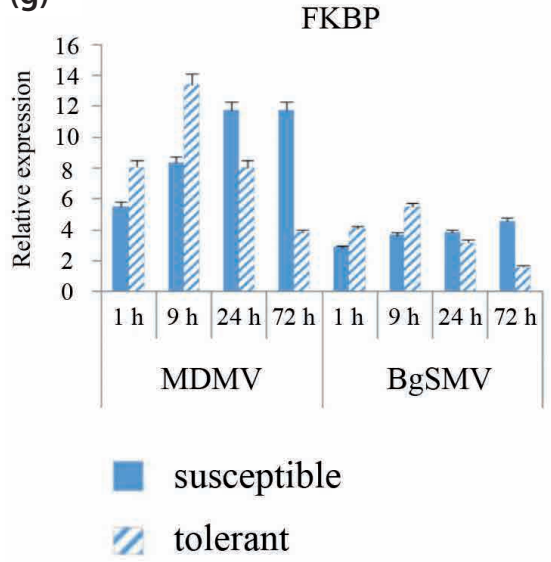

(h)

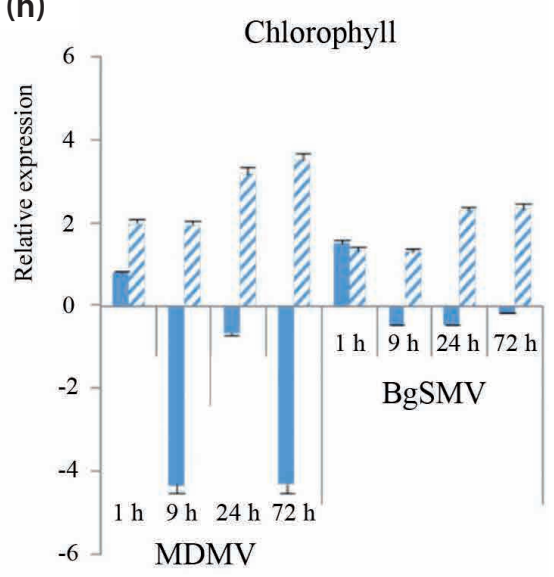

Fig. 3

Gene expression pattern in susceptible and tolerant maize seedlings inoculated by MDMV and BgSMV at different time points In the tolerant maize plants, gene expression is significantly higher than in the susceptible plants during entire experiment. Peroxiredoxin (a), GLP (b), SAM (c), GF14-6 (d), NPR1 (e), MT-LP (f), FKBP (g), chlorophyll a-b binding (h).

days after inoculation (dpi) with MDMV inoculums provided from infected field plants. Maize SC705 cultivar infected with BgSMV showed visible diseases symptoms at $18 \mathrm{dpi}$. 8-hybrid cultivars showed low systemic chlorotic symptoms at 19 dpi with MDMV. In maize leaf samples inoculated with BgSMV, these symptoms were very weak when compared to MDMV infection (Fig. 1b,c and Fig. 2).
qRT-PCR was used to determine the transcript levels of some genes including peroxiredoxin, metallothionein-like protein (MTL), S-adenosyl methionine synthetase (SAM), germin-like protein (GL-P), FKBP, GF 14-6, NPR1 and chlorophyll $a-b$ binding protein in the maize infected by MDMV and BgSMV at 0, 1, 9, 24 and 72 hpi (Fig. 3).

QRT-PCR analysis in the infected maize samples with MDMV and BgSMV, showed a similar pattern of the rela- 
(a)

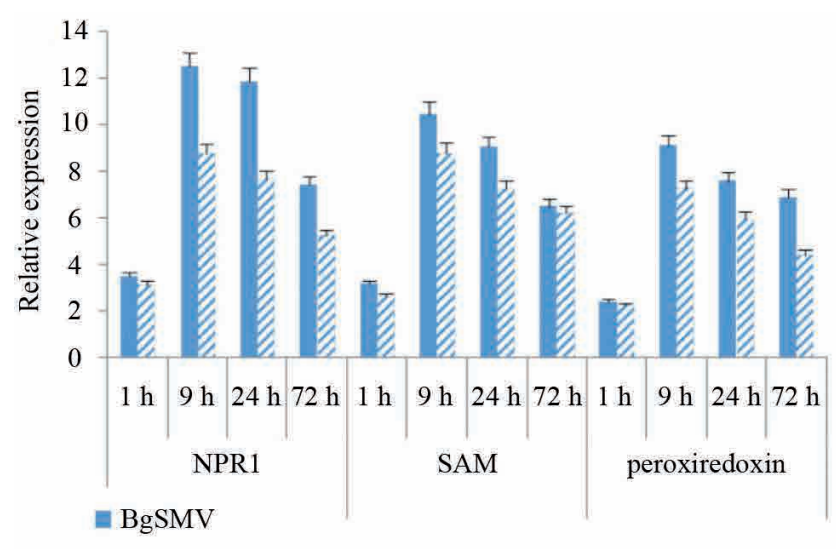

2. MDMV (b)

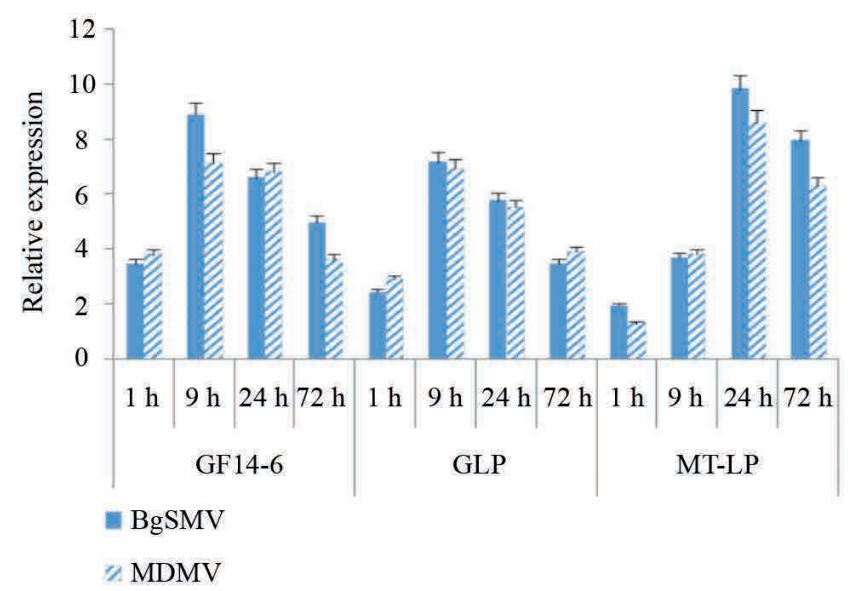

(c)

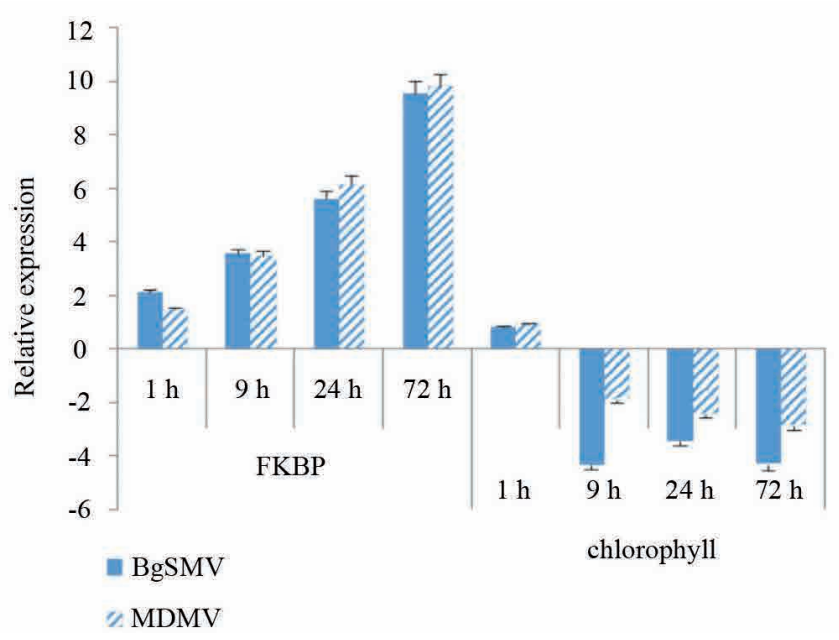

Fig. 4

Gene expression pattern in the Johnson grass plants inoculated by MDMV and BgSMV at different time points

NPR1 (a), SAM (b), peroxiredoxin (c), GF14-6 (d), GLP (e), MT-LP (f), FKBP (g), chlorophyll a-b binding (h). In the Johnson grass plants inoculated by BgSMV, NPR1(a), peroxiredoxin (c) and SAM (b) show higher expression than the plants inoculated by MDMV.

tive expression levels of each investigated gene. One hour after maize inoculation an increase of expression level for all tested genes was seen. During the progresses of MDMV and BgSMV infection, significant changes in all genes has occurred in tolerant maize infected plants compared to sensitive maize infected plants.

At 1 hpi gene expression level of peroxiredoxin and GLP was up-regulated and then followed by a reduction at the 9 , 24 and 72 hpi (Fig. 3a,b).

The expression levels of SAM and GF14-6 genes were elevated in a moderate rate with a continuous increase in the infected maize from first time point after inoculation until last time point of sampling. A maximum 23 and 18- fold rise in expression of SAM and GF14-6 was noted at 2 dpi (Fig. 3c,d).

The expression level of GF14-6 gene didn't show a statistically significant difference in infected tolerant and susceptible maize plants at 1 and 9 hpi while in the $3^{\text {rd }}$ time point after inoculation a significant increase was observed in tolerant cultivar compared to susceptive cultivars (Fig. 3d).

Maximum expression level of three NPR1 (26-fold), MT$L P$ (19-fold) and FKB (14-fold) genes was measured at $9 \mathrm{hpi}$. A considerable reduction of gene expression of three genes was observed in the $2-3$ dpi.

In susceptible maize cultivars infected with MDMV, the expression level of chlorophyll gene increased at all sampling 
(a)

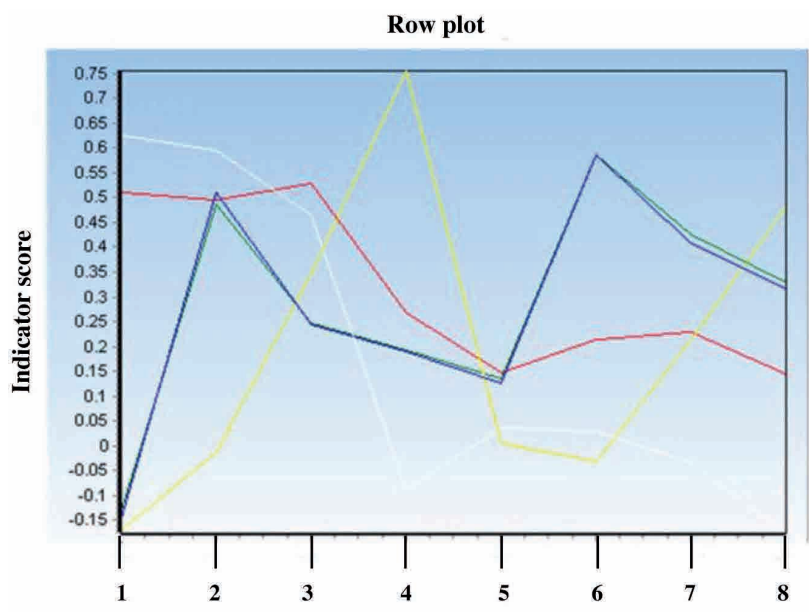

(b)

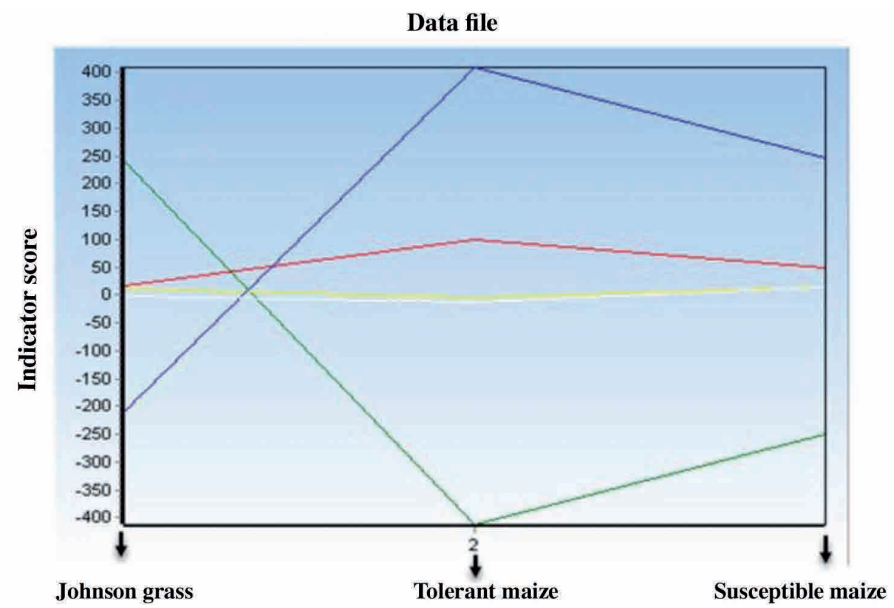

(c)

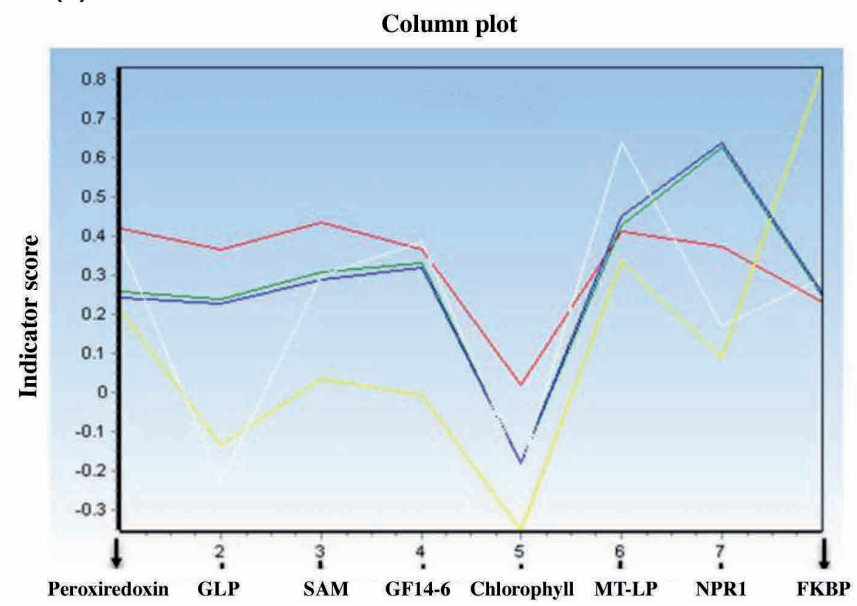

Fig. 5

Trilinear decomposition analysis

(a) Row plots indicates the expression changes over the samples (combination of two viruses with four time points of hpi). Number 1-4: MDMV; 1, 9, 24 and 72 hpi. Number 5-8: BgSMV; 1, 9, 24 and 72 hpi. (b) Data file plot indicates gene expression variation over the genotypes and (c) column plot indicates the expression changes over the genes.

time points. However, unlike in tolerant maize infected plants, chlorophyll gene was suppressed at 9, 24 and $72 \mathrm{hpi}$ while in the susceptible cultivars the expression levels were unregulated at $1 \mathrm{hpi}$ (Fig. 3h).

As showed in Figure 3, a similar pattern of gene expression but with a moderate rate has occurred in the tolerant and susceptible maize infected with BgSMV.

In total, the highest expression level in the infected tolerant maize with MDMV (24.68-fold) and BgSMV (15.2-fold) was related to NPR1 gene at $9 \mathrm{hpi}$ when compared to the control.

The lowest transcription level was seen for chlorophyll gene in both maize genotypes infected with MDMV and BgSMV.
Changes of gene expression in Johnson grass plants inoculated by MDMV and BgSMV

In nature, Johnson grass is not infected with BgSMV. For better understanding of molecular action on this compatibility, we investigated the expression levels of previously tested genes in Johnson grass infected with MDMV and BgSMV. QRT-PCR analysis in infected leaf samples from Johnson grass plants inoculated with MDMV and BgSMV showed that all investigated genes except chlorophyll gene were increased.

The maximum expression level for majority of tested genes has occurred at $9 \mathrm{hpi}$ (Fig. 4). Maximum rate of MT-LP 


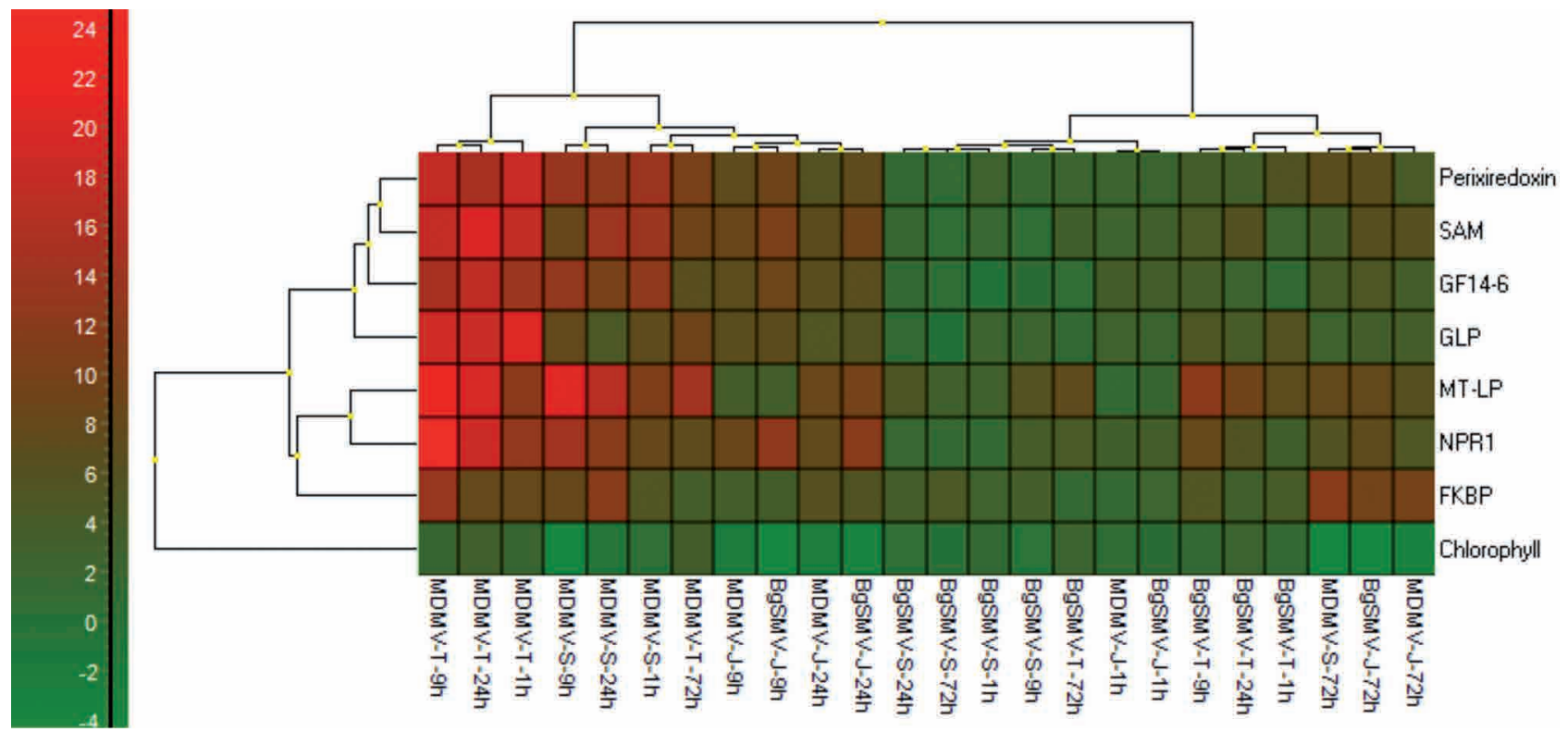

Fig. 6

Gene clustering chart

The genes are located in 4 groups. 1. NPR1 and MT-LP genes; 2. peroxiredoxin, SAM, GF14-6 and GLP; 3. chlorophyll a-b binding and 4. FKBP are in separator groups. ${ }^{* *}$ MDMV-S-1h $(9,24$ and $72 \mathrm{~h})=$ MDMV and susceptible maize at $1 \mathrm{~h}(9,24$ and 72$)$ hpi, MDMV-T-1h $(9,24$ and $72 \mathrm{~h})=\mathrm{MDMV}$ and tolerant maize at $1 \mathrm{~h}(9,24$ and 72$) \mathrm{hpi}, \mathrm{BgSMV}-\mathrm{S}-1 \mathrm{~h}=\mathrm{BgSMV}$ and susceptible maize at $1 \mathrm{~h}(9,24$ and 72$) \mathrm{hpi}, \mathrm{BgSMV}-\mathrm{T}-1 \mathrm{~h}=\mathrm{BgSMV}$ and tolerant maize at $1 \mathrm{~h}$ $(9,24$ and 72$)$ hpi, MDMV-J-1h = MDMV and Johnson grass at $1 \mathrm{~h}(9,24$ and 72$)$ hpi, BgSMV-J-1h = BgSMV and Johnson grass at $1 \mathrm{~h}(9,24$ and 72$)$ hpi.

and FKBP genes expression was recorded at the 24 and 72 hpi, respectively. The chlorophyll $a-b$ binding transcripts in Johnson grass infected with MDMV and BgSMV did not show significant difference at $1 \mathrm{hpi}$ compared to non-infected plants. Gene expression level was significantly decreased at the 9, 24 and 72 hpi and at these time points after inoculation with both viruses, the chlorophyll gene was suppressed. The rate of this suppression was approximately similar in third time of sampling after inoculation. All changes of expression in compatible or non-compatible Johnson grass plants infected by MDMV and BgSMV are shown in Fig. 4.

\section{Trilinear decomposition analysis and clustering of genes}

Inspecting the underlying components, green and blue principle component (PC) curves were quite similar in the row plot (Fig. 5a). Looking at the data file plot, PCs show extreme values for tolerant maize genotype, therefore, the maximum variation in gene expression belongs to this genotype (Fig. 5b). It was concluded from the row plot that a maximum gene expression response occurred against BgSMV at 9 hpi. Based on the highest indicator score of green and blue PCs, it was understood that NPR1 and MT-LP genes are important in tolerant maize genotype by looking at the columns plot (Fig. 5c).
Gene clustering chart designed based on host genotype, time of infection, and viral strains showed that all investigated genes are located in 4 groups based on their expression. NPR1 and MT-LP genes are placed in one group, peroxiredoxin, $S A M, G F 14-6$ and GLP are in other separated group and chlorophyll $a-b$ binding and FKBP are in two single groups (Fig. 6).

Results of gene clustering showed that NPR1 and MT-LP genes are located in one group, indicating that related expression of these genes could be co-regulated in the different states (Fig. 6).

\section{Discussion}

Maize dwarf mosaic virus (MDMV) is one of the most important biotic stressors of cultivated maize varieties. The infection usually causes a considerable loss of crop. In this study, molecular changes at the level of gene expression were studied to illustrate host specificity of maize and Johnson grass infected by MDMV and BgSMV viruses. The development of MDMV was monitored over 18 days after virus inoculation. The mosaic symptoms were observed in new appearing leaves. The results were similar to the reported data by other researchers (Uzarowska et al., 2009). In maize com- 
patible to virus infection, biotic and abiotic stress responses are detectable in the infected leaves (Ludmerszki et al., 2014). The BgSMV is very similar to MDMV with some differences at the level of disease symptoms and biochemical traits. It has been reported that BgSMV has one 90 nucleotide region (position 108 to 198) related to 5'-region of coat protein gene more than MDMV. The differentiation between the two viruses by ELISA is not possible. Also, BgSMV is compatible, while MDMV is incompatible to Johnson grass host. In this paper, the seedling leaves sample infected by MDMV and BgSMV were harvested at 1-72 hpi and then the leave-less plants were monitored up to $18 \mathrm{dpi}$. In the all susceptible and tolerant plants, the expression level of all investigated genes was increased at the first-hour post infection. This is a rapid response indicator of proliferation and replication of MDMV and BgSMV viruses. This virus progress at the first time point after inoculation quickly makes the defense reaction a lot stronger, because the production of pathogenesis related proteins increase resistance mechanism pathways. In infected plants with various viruses belonging to the Potyvirus family; activation of some related-defense genes has been immediately increased after the first time point of infection (Maule et al., 2002; Marathe et al., 2004; Love et al., 2005; Uzarowska et al., 2009) and these results are in concordance with our data in this work. Specific symptoms in same plants infected with related viruses displaying common symptoms suggest linked changes to resistance responses and could help us to identify common resistance candidate genes (Dardick, 2007). Gene expression analysis by microarray approach in infected maize (Zea mays L.) with MDMV and SCMV viruses indicated that the SAM and GF14-6 genes coding for metallothionein-like protein, S-adenosylmethionine synthetase, and germin-like protein 4, respectively were differentially expressed at significant levels (Użarowska et al., 2009). In this research, the expression level of SAM and GF14-6 genes in tolerant plants differentially changed at different time points after both viral infections. Increased expression level of putative genes in infected plants during virus development; propose that expression changes of defense-related genes might be associated with symptom development. Our findings show that the majority of investigated genes were up-regulated in Johnson grass plants inoculated by BgSMV compared to MDMV infection. Based on these results, we can suggest a possible identification of plant resistance using these genes as biomarkers.

Normally, in resistant and tolerant plants, a virus resistance gene has to be expressed before pathogen attacks. So, this state can lead to rapid resistance response after infection. Based on this theory, a high expression level of defense-related genes at the first time point after inoculation is anticipated. In this study the highest regulation was observed for NPR1 gene. NPR1 as a key regulator of systemic acquired resistance (SAR) which can enhance the expression level of a large numbers of pathogenesis related proteins (PR protein) to general stress responses. Proteomic analysis of infected Capsicum annum with TMV revealed 7 up-regulated PR-proteins through NPR1 pathway (Elvira et al., 2008). Trilinear decomposition analysis showed the maximum variation of NPR1 and MT-LP genes among three infected genotypes with both MDMV and BgMV viruses. In previous work we showed the important and key role of NPR1 gene in resistance induction in infected tomato plants with Ralstonia solanacearum by using virus induced gene silencing (VIGS) method (Bolok Yazdi et al., 2018). To confirm the critical role of NPR1 and MT-LP genes microarray and VIGS analysis with infected tolerant maize plants with different virus from same family is proposed. Gene clustering pattern indicated that NPR1 and MT-LP are placed in a common group, so we could conclude that both genes have the same importance in enhancement of plant disease resistance against viral infection.

\section{References}

Bolok Yazdi HR, Sabbagh SK, Mazaheri M, Salari M, Moshtaghioun SM (2018): Virus-induced gene silencing for functional analysis of eds1 gene in tomato infected with Ralstonia solanacearum. Zemdirbyste-Agriculture 105, 357-362. https://doi.org/10.13080/z-a.2018.105.045

Campo S, Peris-Peris C, Montesinos L, Penas G, Messeguer J, Segundo BS (2012): Expression of the maize ZmGF14-6 gene in rice confers tolerance to drought stress while enhancing susceptibility to pathogen infection. J. Exp. Botany. 63, 983-999. https://doi.org/10.1093/jxb/err328

Chen F, Li Q, Sun L, He Z (2006): The rice 14-3-3 gene family and its involvement in responses to biotic and abiotic stress. DNA Res. 13, 53-63. https://doi.org/10.1093/dnares/dsl001

Cueto-Ginzo I, Serrano L, Sin E, Rodriguez R, Morales J, Lade S, Medina V, Achon M (2016): Exogenous salicylic acid treatment delays initial infection and counteracts alterations induced by Maize dwarf mosaic virus in the maize proteome. Physiol. Mol. Plant Pathol. 96, 47-59. https:// doi.org/10.1016/j.pmpp.2016.07.001

Dardick C (2007): Comparative expression profiling of Nicotiana benthamiana leaves systemically infected with three fruit tree viruses. Mol. Plant Microbe Interact. 20, 1004-1017. https://doi.org/10.1094/MPMI-20-8-1004

Elvira MI, Galdeano MM, Gilardi P, García-Luque I, Serra MT (2008): Proteomic analysis of pathogenesis-related proteins (PRs) induced by compatible and incompatible interactions of pepper mild mottle virus (PMMoV) in Capsicum chinense L 3 plants. J. Exp. Botany. 59, 1253-1265. https://doi.org/10.1093/jxb/ern032

Gökirmak T, Paul AL, Ferl RJ (2010): Plant phosphopeptide-binding proteins as signaling mediators. Curr. Opin. Plant Biol. 13, 527-532. https://doi.org/10.1016/j.pbi.2010.06.001

Gomez-Gomez L, Carrasco P (1998): Differential expression of the $\mathrm{S}$-adenosyl-L-methionine synthase genes during pea 
development. Plant. Physiol. 117, 397-405. https://doi. org/10.1104/pp.117.2.397

Hamer DH (1986): Metallothionein. Annu. Rev. Biochem. 55, 913-951. https://doi.org/10.1146/annurev. bi.55.070186.004405

Hao Z, Wang L, Huang F, Tao R (2012): Expression of defense genes and antioxidant defense responses in rice resistance to neck blast at the preliminary heading stage and full heading stage. Plant. Physiol. Biochem. 57, 222-230. https://doi.org/10.1016/j.plaphy.2012.05.009

Hartl FU, Hayer-Hartl M (2002): Molecular chaperones in the cytosol: from nascent chain to folded protein. Science. 295, 1852-1858. https://doi.org/10.1126/science.1068408

Haslekas C, Viken MK, Grini PE, Nygaard V, Nordgard SH, Meza TJ, Aalen RB (2003): Seed 1-cysteine peroxiredoxin antioxidants are not involved in dormancy, but contribute to inhibition of germination during stress. Plant. Physiol. 133, 1148-1157. https://doi.org/10.1104/pp.103.025916

Konagaya KI, Matsushita Y, Kasahara M, Nyunoya H (2004): Members of 14-3-3 protein isoforms interacting with the resistance gene product $\mathrm{N}$ and the elicitor of Tobacco mosaic virus. J. Gen. Plant. Pathol. 70, 221-231. https:// doi.org/10.1007/s10327-003-0113-4

Lane BG (2002): Oxalate, Germins, and Higher-Plant Pathogens. IUBMB life 53, 67-75. https://doi.org/10.1080/ $\underline{15216540211474}$

Love AJ, Yun BW, Laval V, Loake GJ, Milner JJ (2005): Cauliflower mosaic virus, a compatible pathogen of Arabidopsis, engages three distinct defense-signaling pathways and activates rapid systemic generation of reactive oxygen species. Plant. Physiol. 139, 935-948. https://doi.org/10.1104/ pp. 105.066803

Ludmerszki E, Almasi A, Racz I, Szigeti Z, Solti A, Olah C, Rudnoy S (2015): S-methylmethionine contributes to enhanced defense against maize dwarf mosaic virus infection in maize. Braz. J. Bot. 38, 771-782. https://doi.org/10.1007/ $\underline{\text { s40415-015-0195-1 }}$

Ludmerszki E, Racz I, Rudnoy SZ (2014): S-methylmethionine alters gene expression of candidate genes in Maize dwarf mosaic virus infected and drought stressed maize plants. Acta. Biol. Szeged. 58, 1-5.

Marathe R, Guan Z, Anandalakshmi R, Zhao H, Dinesh-Kumar S (2004): Study of Arabidopsis thaliana resistome in response to Cucumber mosaic virus infection using whole genome microarray. Plant. Mol. Biol. 55, 501-520. https:// doi.org/10.1007/s11103-004-0439-0

Masumi M, Zare A, Izadpanah K (2011a): Biological, serological and molecular Comparisons of potyviruses infecting poaceous plants in Iran. Iran. J. Plant Pathol. 47, 47-66.
Masumi M, Zare A, Izadpanah K (2011b): Biological, serological and molecular comparisons of potyviruses infecting poaceous plants in Iran. Iran. J. Plant Pathol. 47, 11-14.

Maule A, Leh V, Lederer C (2002): The dialogue between viruses and hosts in compatible interactions. Curr. Opin. Plant Biol. 5, 279-284. https://doi.org/10.1016/S1369-5266(02)00272-8

Mostafavi FS, Masumi M, Nasrollanejad S, Rahpeymasarvestani N, Izadpanah K (2015): Analyses of complete nucleotide sequence of Iranian isolate of Maize dwarf mosaic virus (MDMV) and notes on the origin and evolution of MDMV. Iran. J. Plant Pathol. 51, 69-81.

Oh CS, Pedley KF, Martin GB (2010): Tomato 14-3-3 protein 7 positively regulates immunity-associated programmed cell death by enhancing protein abundance and signaling ability of MAPKKK $\alpha$. The Plant Cell 22, 260-272. https:// doi.org/10.1105/tpc.109.070664

Pfaffl MW (2001): A new mathematical model for relative quantification in real-time RT-PCR. Nucleic Acids Res. 29, 2002-2007. https://doi.org/10.1093/nar/29.9.e45

Singh RK, Anandhan S, Singh S, Patade VY, Ahmed Z, Pande V (2011): Metallothionein-like gene from Cicer microphyllum is regulated by multiple abiotic stresses. Protoplasma 248, 839-847. https://doi.org/10.1007/s00709-010-0249-y

Uzarowska A, Dionisio G, Sarholz B, Piepho HP, Xu M, Ingvardsen CR, Wenzel G, Lübberstedt T (2009): Validation of candidate genes putatively associated with resistance to SCMV and MDMV in maize (Zea mays L.) by expression profiling. BMC Plant Biol. 9, 15. https://doi. org/10.1186/1471-2229-9-15

Wang W, Ma Q, Xiang Y, Zhu S, Cheng B (2012): Genome-wide analysis of immunophilin FKBP genes and expression patterns in Zea mays. Genet. Mol. Res. 11 2, 1690-1700. https://doi.org/10.4238/2012.June.25.2

Wu L, Han Z, Wang S, Wang X, Sun A, Zu X, Chen Y (2013): Comparative proteomic analysis of the plant-virus interaction in resistant and susceptible ecotypes of maize infected with sugarcane mosaic virus. J. Proteom. 89, 124-140. https://doi.org/10.1016/j.jprot.2013.06.005

Zare A, Masumi M, Izadpanah K (2005): Bermuda grass southern mosaic virus: a distinct Potyvirus infecting several gramineous species in Iran. Parasitica 61, 105-110.

Zimmermann G, Baumlein H, Mock H, Himmelbach A, Schweizer $P$ (2006): The multigene family encoding germin-like proteins of barley: regulation and function in basal host resistance. Plant. Physiol. 142, 181-192. https://doi. org/10.1104/pp.106.083824 